\title{
Operando Calorimetry Informs the Origin of Rapid Rate Performance in Microwave-Prepared $\mathrm{TiNb}_{2} \mathrm{O}_{7}$
}

\section{Electrodes}

Sun Woong Baek ${ }^{\mathrm{a}}$, Kira E. Wyckoff ${ }^{\mathrm{b}}$, Danielle M. Butts ${ }^{\mathrm{c}}$, Jadon Bienz ${ }^{\mathrm{d}}$, Ampol Likitchatchawankun ${ }^{\mathrm{a}}$, Molleigh B. Preefer ${ }^{\mathrm{b}}$, Matevž Frajnkoviča ${ }^{\mathrm{a}}$, Bruce S. Dunn ${ }^{\mathrm{c}, \mathrm{e}}$, Ram Seshadri ${ }^{\mathrm{b}, \mathrm{d}}$, and Laurent Pilon ${ }^{\mathrm{a}, \mathrm{e}, \mathrm{f},+}$

${ }^{a}$ Mechanical and Aerospace Engineering Department, Henry Samueli School of Engineering and Applied Science, University of California, Los Angeles, CA 90095, USA

baterials Department, and Materials Research Laboratory, University of California, Santa Barbara, CA 93106, USA

${ }^{\mathrm{c}}$ Department of Materials and Engineering, Henry Samueli School of Engineering and Applied Science, University of California, Los Angeles, CA 90095, USA

${ }^{\mathrm{d}}$ Department of Chemistry and Biochemistry, University of California, Santa Barbara, CA 93106, USA

${ }^{\text {e}}$ California NanoSystems Institute, University of California, Los Angeles, Los Angeles, California 90095, USA

${ }^{\mathrm{f}}$ Institute of the Environment and Sustainability, University of California, Los Angeles, Los Angeles, California 90095, USA

${ }^{+}$Corresponding Author: Phone: +1 (310)-206-5598, Fax: +1 (310)-206-2302

E-mail: pilon@seas.ucla.edu

October 11, 2020 


\section{Abstract}

The shear-phase compound $\mathrm{TiNb}_{2} \mathrm{O}_{7}$ has recently emerged as a safe and high-volumetric density replacement for graphite anodes in lithium ion batteries. An appealing feature of $\mathrm{TiNb}_{2} \mathrm{O}_{7}$ is that it retains capacity even at high cycling rates. Here we demonstrate that phase pure and crystalline $\mathrm{TiNb}_{2} \mathrm{O}_{7}$ can be rapidly prepared using a high-temperature microwave synthesis method. Studies of the charging and discharging of this material, including through operando calorimetry, permit key thermodynamic parameters to be revealed. The nature of heat generation is dominated by Joule heating, which sensitively changes as the conductivity of the electrode increases with increasing lithiation. The enthalpy of mixing, obtained from operando calorimetry, is found to be small across the different degrees of lithiation pointing to the high rate of lithium ion diffusion at the origin of rapid rate performance.

\section{Graphical Abstract}

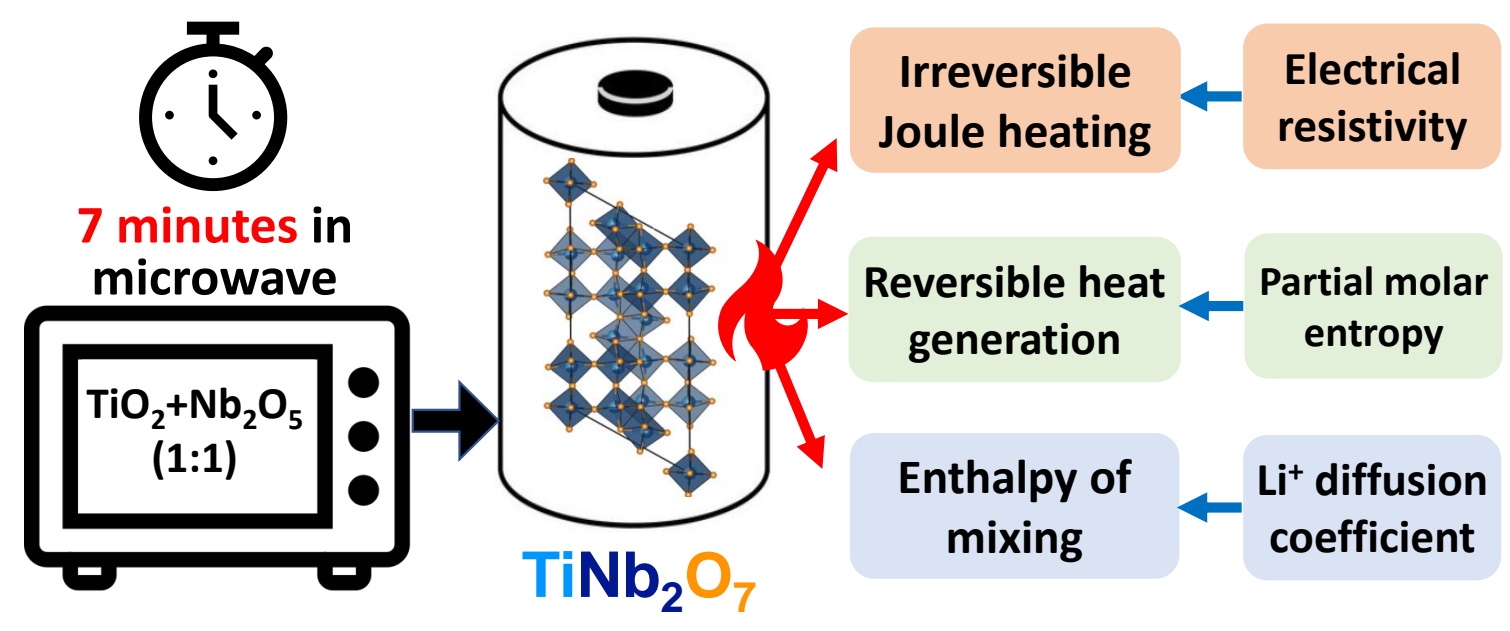




\section{Introduction}

Fast charging electrical energy storage devices with high energy density, compact size, and long-life have received significant research interest driven by the remarkable increase in demand for portable consumer electronics and electric vehicles (EV) [1-4]. In this context, lithium-ion batteries (LIBs) with high energy density and low environmental impact have received particular attention [5]. Graphite has been widely used as an anode material in LIBs owing to its low cost, structural stability upon cycling, and high energy density [6,7]. However, graphite anodes suffer from performance degradation over time caused by the formation of a passivating solid-electrolyte interface (SEI) layer due to its low operating voltage of 0.1 $\mathrm{V}$ (versus $\mathrm{Li} / \mathrm{Li}^{+}$) $[8,9]$. Furthermore, the plating of lithium on the SEI layer degrades the kinetics of the redox reaction thus limiting the charging rate of the LIBs [10,11]. Therefore, graphite anodes are not suitable for fast charging applications. To address the challenges associated with graphite anodes, many alternative transition metal oxides have been developed including $\mathrm{TiO}_{2}[12-14], \mathrm{LiCrTiO}_{4}[15,16]$, and $\mathrm{Li}_{4} \mathrm{Ti}_{5} \mathrm{O}_{12}$ [17-19]. In fact, $\mathrm{Li}_{4} \mathrm{Ti}_{5} \mathrm{O}_{12}$ features an operating potential plateau of approximately $1.5 \mathrm{~V}$ (versus $\mathrm{Li} / \mathrm{Li}^{+}$) and has been a leading candidate due to its relatively abundant and non-toxic elements and its structural stability upon cycling [20]. However, $\mathrm{Li}_{4} \mathrm{Ti}_{5} \mathrm{O}_{12}$ features relatively low specific capacity ( $\sim 160$ mAh/g) [11]. Recently, $\mathrm{TiNb}_{2} \mathrm{O}_{7}$ has been proposed as an alternative anode material [21]. Based on five lithium insertion per formula unit, $\mathrm{TiNb}_{2} \mathrm{O}_{7}$ has a theoretical specific capacity of $388 \mathrm{mAh} / \mathrm{g}$ and a theoretical volumetric capacity of $1680 \mathrm{mAh} / \mathrm{cm}^{3}$, i.e., twice as large as that of graphite [22]. $\mathrm{TiNb}_{2} \mathrm{O}_{7}$ has been synthesized through different solid-state $[21,23]$ and hydrothermal [24] methods. Unfortunately, these methods require long heat treatments. For instance, the conventional solid-state method requires heat treatment at temperature $\geq$ $1000{ }^{\circ} \mathrm{C}$ for approximately 24 hours $[21,23]$ while the hydrothermal method requires heat treatment at temperature $\geq 1100{ }^{\circ} \mathrm{C}$ for 12 hours [24].

The present study aims to develop a fast, simple, and cost-effective synthesis method of $\mathrm{TiNb}_{2} \mathrm{O}_{7}$ for LIB anode electrodes. The materials synthesized and the associated electrodes were characterized by high-resolution synchrotron X-ray diffraction (XRD) technique, 
conventional electrochemical methods, and potentiometric entropy measurement technique. Finally, operando calorimetric measurements were used to deepen our understanding of the lithiation/delithiation process in $\mathrm{TiNb}_{2} \mathrm{O}_{7}$ electrodes and to investigate the associated heat generation upon cycling at high C-rates.

\section{Background}

Four main phenomena contribute to heat generation in LIBs including (i) Joule heating, (ii) reversible entropic heat generation, (iii) heat of mixing, and (iv) undesirable side reactions [25-28]. Joule heating corresponds to irreversible resistive losses in the battery with an associated heat generation rate expressed as $\dot{Q}_{J}(x, t)=R_{I}(x) I^{2}$ where $R_{I}(x)$ is the battery

internal resistance at lithium composition $x$. Alternatively, $\dot{Q}_{J}(x, t)$ can be expressed as a function of the applied current $I$ and the battery overpotential defined as the difference between the operating voltage $V(x, t)$ and the open circuit voltage $U_{o c v}(x, T)$, i.e. [25-28],

$$
\dot{Q}_{J}(x, t)=I\left[V(x, t)-U_{o c v}(x, T)\right]
$$

The overpotential in the device can be interpreted as the voltage drop due to the LIB's internal resistance. The latter is influenced by many factors and their effects have been discussed extensively in the literature [33]. In brief, the battery internal resistance is known to increase with (i) increasing number of cycles [31,32], (ii) increasing charge-transfer resistance [34], (iii) decreasing ionic conductivity [34], and (iv) increasing electrolyte viscosity [36]. Additionally, the impact of changes in the state of charge (SOC) on the internal resistance upon lithiation/delithiation varies significantly with cell chemistry since the battery materials often experience phase transitions. The internal resistance of LIBs can be measured for different lithium compositions using ex situ techniques [37]. Even though these methods can be used to evaluate the changes in internal resistance at different SOC, it cannot capture the change in internal resistance during cycling. Operando calorimetry offers an alternative technique to evaluate the LIB's internal resistance during cycling. 
The reversible entropic heat generation rate $\dot{Q}_{r e v}(x, t)$ due to entropic changes in the electrode upon lithiation/delithiation can be expressed as [25-28]

$$
\dot{Q}_{r e v}(x, t)=I T \frac{\partial U_{o c v}(x, T)}{\partial T}=I T \frac{\bar{s}(x, T)}{n F} .
$$

Here, $\bar{s}(x, T)=n F \partial U_{o c v}(x, T) / \partial T$ is the partial molar entropy of the cell, $T$ is the temperature of the cell, $n$ is the number of electrons transferred by a single ion, and $F$ is the Faraday constant. Note that the derivative $\partial U_{o c v}(x, T) / \partial T$ is often termed as the entropic potential and varies significantly with the SOC and any phase transitions in the cell upon lithiation/delithiation [28].

The heat of mixing also known as enthalpy of mixing $\dot{Q}_{m i x}(x, t)$ associated with ion concentration gradients caused by mass transfer resistance in the system can be written as $[25-27]$

$$
\dot{Q}_{m i x}(x, t)=-\int_{V_{\infty}} \sum_{i}\left[\bar{h}_{i}(x, T)-\bar{h}_{i}^{a v g}(x, T)\right] \frac{\partial c_{i}}{\partial t} d V .
$$

Here, $V_{\infty}$ is the volume of the cell, $\bar{h}_{i}(x, T)$ is the partial molar enthalpy of species $i$ evaluated at the volume-averaged concentration at time $t$, and $c_{i}$ is the local concentration of species $i$. For LIBs, the enthalpy of mixing can be further divided into four different contributions associated with ionic concentration gradients (i) across the electrolyte due to mass transfer, (ii) across the electrode due to non-uniform current distribution, (iii) within lithium vacancies in the electrode due to electrochemical reactions, and (iv) within the lithium ions intercalated into the electrode from electrochemical reactions $[38,39]$. Among these different contributions, the enthalpy of mixing caused by the concentration gradient of the intercalated lithium ions within the electrode is the most significant [27]. Note that $\dot{Q}_{m i x}(x, t)$ is often negligible at low C-rates. However, $\dot{Q}_{m i x}(x, t)$ has to be considered for fast charging battery applications since it can be significant at high C-rates [26]. In fact, a previous study [38] reported that the energy dissipated as enthalpy of mixing in a cell consisting of $\mathrm{LiAl}_{0.2} \mathrm{Mn}_{1.8} \mathrm{O}_{4-\delta} \mathrm{F}_{0.2}$ as the cathode, $\mathrm{LiPF}_{6}$ in EC:DMC 1:1 v/v as the electrolyte, and lithium metal as anode represented about $1.3 \%$ of the total energy dissipated as heat at C-rate of $\mathrm{C} / 3$. However, it reached to $52 \%$ at C-rate of $2 \mathrm{C}$. Therefore, the enthalpy of mixing must be accounted for 
when considering heat generation in fast charging batteries.

Finally, the heat generation due to undesirable side reactions $\dot{Q}_{s r}(x, t)$ can be expressed as $[25-27]$

$$
\dot{Q}_{s r}(x, t)=-\sum_{i} \Delta H_{i} \dot{r}_{i}(t)
$$

where $\Delta H_{i}$ is the enthalpy of reaction of chemical reaction $i$ occurring at reaction rate $\dot{r}_{i}(t)$. Previous studies on heat generation in LIBs have neglected $\dot{Q}_{s r}(x, t)$ [25-28]. In fact, the

aging process of LIBs occurs at relatively slow rates [25] and the magnitude of $\dot{Q}_{s r}(x, t)$ is much smaller than that of $\dot{Q}_{J}(x, t), \dot{Q}_{\text {rev }}(x, t)$, and $\dot{Q}_{m i x}(x, t)$ under normal operation [26]. Overall, the total instantaneous heat generation rate $\dot{Q}_{T}(x, t)$ (in $W$ ) in the entire cell can be written as sum of all those four terms, i.e. [25-28],

$$
\dot{Q}_{T}(x, t)=\dot{Q}_{J}(x, t)+\dot{Q}_{r e v}(x, t)+\dot{Q}_{m i x}(x, t)+\dot{Q}_{s r}(x, t)
$$

Here, $\dot{Q}_{T}(x, t)$ is positive when heat is released by the cell and negative when heat is absorbed by the cell.

\section{Materials and methods}

\subsection{Microwave synthesis of $\mathrm{TiNb}_{2} \mathrm{O}_{7}$}

In this study, $\mathrm{TiNb}_{2} \mathrm{O}_{7}$ particles were synthesized using a fast and simple method consisting of a single heating step in a microwave oven under ambient atmosphere. First, the precursor powders $\mathrm{TiO}_{2}$ (Aldrich Chemical Company, 99\%) and $\mathrm{Nb}_{2} \mathrm{O}_{5}$ (Materion, 99.95\%) were thoroughly ground together in stoichiometric quantities (1:1) using an agate mortar and pestle. The ground powder was then pressed into $250 \mathrm{mg}$ to $300 \mathrm{mg}$ pellets using a hand-operated arbor press. The pellets were placed on a small sacrificial powder layer of the same material inside of a $10 \mathrm{~mL}$ alumina crucible. This crucible was then nestled into a larger $20 \mathrm{~mL}$ alumina crucible filled with approximately $7 \mathrm{~g}$ of activated charcoal covered in alumina fiberboard insulation, and placed off-center in a $1200 \mathrm{~W}$ microwave oven (Panasonic). This stack was heated at $90 \%$ of the total microwave power for 7 minutes reaching temperatures around 
$1200{ }^{\circ} \mathrm{C}$, as observed with a laser thermometer, immediately upon reaction completion. The insulation was removed and the pellets were allowed to cool to room temperature.

\subsection{Structural characterization}

High resolution synchrotron X-ray diffraction measurements of the synthesized $\mathrm{TiNb}_{2} \mathrm{O}_{7}$ powder were collected at room temperature at the Advanced Photon Source at Argonne National Laboratories on beamline 11-BM-B using an average wavelength of $0.457856 \AA$. The $\mathrm{TiNb}_{2} \mathrm{O}_{7}$ powder sample was loaded into a Kapton capillary and both ends were sealed with clay. Rietveld refinement was performed with TOPAS [40] while VESTA [41] was used for crystal structure visualization.

\subsection{Electrochemical testing}

The electrodes were cast on copper foil using an 80:10:10 (wt\%) ratio of active material $\left(\mathrm{TiNb}_{2} \mathrm{O}_{7}\right)$, conductive carbon (TIMCAL SuperP), and polyvinylidene fluoride (Sigma Aldrich). The active material was ball-milled for 30 minutes in a $2 \mathrm{~cm}^{3}$ canister with SuperP. This mixture was added to PVDF dissolved in 1-methyl-2-pyrrolidinone (Sigma Aldrich) to form a slurry and was mixed in a FlackTek speed mixer at $2000 \mathrm{rpm}$ for 30 minutes. The slurry was cast onto a copper foil using a doctor blade set for $150 \mu \mathrm{m}$. Then, the film was dried overnight at $110{ }^{\circ} \mathrm{C}$ in a vacuum oven. The fabricated electrode was then punched into $10 \mathrm{~mm}$ diameter discs resulting in an active material loading of $5.6 \mathrm{mg} / \mathrm{cm}^{2}$ and assembled into a coin cell configuration (MTI parts, $2032 \mathrm{SS}$ casings) with $1 \mathrm{M}$ of $\mathrm{LiPF}_{6}$ in EC:DMC $1: 1 \mathrm{v} / \mathrm{v}$ (Sigma Aldrich) as electrolyte and polished lithium metal (Sigma Aldrich) as the counter electrode with a $50 \mu \mathrm{m}$ thick polypropylene/polyethylene separator (Celgard C380). Cyclic voltammetry $(\mathrm{CV})$, galvanostatic cycling $(\mathrm{CC})$, and galvanostatic intermittent titration technique (GITT) were performed on the coin cell in the voltage range of 1.0-3.0 V using a high accuracy potentiostat (Biologic, VSP-300). During GITT, each current pulse was applied for 1 minute followed by a relaxation period of 30 minutes to measure the open circuit voltage $U_{\text {ocv }}(x, T)$ as a function of composition $x$ in $\mathrm{Li}_{x} \operatorname{TiNb}_{2} \mathrm{O}_{7}$ at constant temper- 
ature $T=20{ }^{\circ} \mathrm{C}$. All potentials in this study are reported relative to $\mathrm{Li}^{+} / \mathrm{Li}$, and C-rates are defined with respect to the reduction of one electron per transition metal, e.g., $1 \mathrm{C}=233$ $\mathrm{mAh} / \mathrm{g}$.

\subsection{Potentiometric entropy measurement}

The partial molar entropy $\bar{s}(x, T)$ of the $\mathrm{TiNb}_{2} \mathrm{O}_{7}$ half-cell was measured as a function of lithium composition $x$ using a potentiometric entropy measurement technique performed on a coin cell. The lithium metal counter electrode was considered as an infinite $\mathrm{Li}^{+}$reservoir with no lattice rearrangement upon lithiation/delithiation [29]. Therefore, the contribution of the lithium metal electrode to the partial molar entropy was assumed to be constant throughout the cycle $[30,43]$. The entropic potential of the $\mathrm{TiNb}_{2} \mathrm{O}_{7}$ coin cell $\partial U_{\text {ocv }}(x, T) / \partial T$ was measured to determine the partial molar entropy $\bar{s}(x, T)$ using Eq.(2).

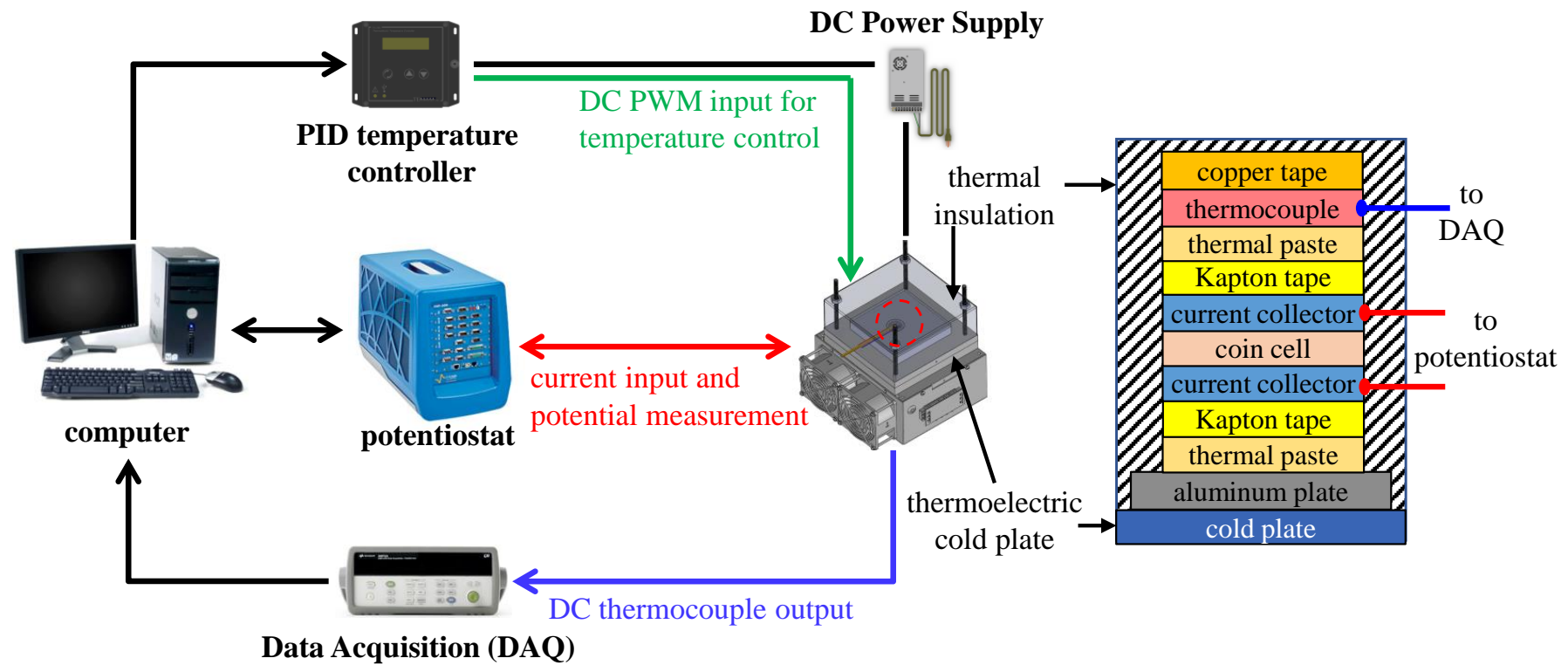

Figure 1: Schematic of the experimental setup used for the potentiometric entropy measurement.

Figure 1 shows the schematic of the custom-made experimental setup assembled for potentiometric entropy measurements. The experimental setup consisted of a thermoelectric 
cold plate (TE technology, CP-121) whose temperature was measured by a type-K thermocouple (Omega, GG-KI-24S-200) via a data acquisition system (Keysight, Agilent 34972A). The temperature of the cold plate was controlled by a proportional-integral-derivative (PID) temperature controller (TE technology, TC-720). The coin cell and current collectors were wrapped with Kapton tape to prevent electrical contact with the thermoelectric cold plate. Thermal paste (Omega, OT-201-16) was applied between the thermoelectric cold plate and the wrapped coin cell to ensure good thermal contact. The type-K thermocouple was secured on top of the coin cell assembly with the thermal paste and covered by a copper tape for accurate temperature measurements. The entire setup was thermally insulated with Styrofoam to reduce heat losses to the surrounding and achieve precise control of the coin cell temperature.

The potentiometric entropy measurements consisted of imposing a series of constant current pulses at a C-rate of $2 \mathrm{C}$ for one minute at $20{ }^{\circ} \mathrm{C}$ each followed by a relaxation period of 90 minutes. During the relaxation, a step-like temperature profile was applied to the coin cell from $15{ }^{\circ} \mathrm{C}$ to $25^{\circ} \mathrm{C}$ in $5{ }^{\circ} \mathrm{C}$ increments. The resulting voltage profile was recorded with the potentiostat (Biologic, VSP-300). Before recording the open circuit voltage $U_{\text {ocv }}(x, T)$ and imposing the next temperature step, we verified that the cell was in thermodynamic equilibrium by making sure that (i) the temperature difference between the cold plate and the top of the coin cell was less than $0.1{ }^{\circ} \mathrm{C}$ and (ii) the time rate of change of the open circuit voltage $\partial U_{o c v} / \partial t$ was less than $1 \mathrm{mV} / \mathrm{h}$.

\subsection{Operando isothermal calorimetry}

The instantaneous heat generation rate in the $\mathrm{TiNb}_{2} \mathrm{O}_{7}$ half-cell was measured under galvanostatic cycling using a custom-made isothermal calorimeter previously described [44]. The $\mathrm{TiNb}_{2} \mathrm{O}_{7}$ electrode was cut into a $1 \times 1 \mathrm{~cm}^{2}$ square and assembled into a calorimetric cell with $1 \mathrm{M} \mathrm{LiPF}_{6}$ in EC:DMC 1:1 v/v (Sigma Aldrich) as electrolyte and polished lithium metal ribbon (Sigma Aldrich) as counter electrode with a $50 \mu \mathrm{m}$ thick Celgard C380 polypropylene/polyethylene separator. Based on the thermal analysis of a single electrode 
described in Supplementary Materials of Ref. [44], the heat generation rate $\dot{Q}_{i}(t)$ (in mW) at each electrode was equal to the heat transfer rate $q_{i}^{\prime \prime}(t)$ passing through the $1 \times 1 \mathrm{~cm}^{2}$ thermoelectric heat flux sensor (greenTEG, gSKIN-XP) such that [44],

$$
\dot{Q}_{i}(t)=q_{i}^{\prime \prime}(t) A_{i}=\frac{\Delta V_{i}(t)}{S_{i}} A_{i} \quad \text { with } i=+ \text { or }-
$$

where $A_{i}$ denotes the footprint area of the electrode (in $\mathrm{cm}^{2}$ ) while $S_{i}$ is the temperaturedependent sensitivity of the heat flux sensor provided by the manufacturer (in $\mu \mathrm{V} /\left(\mathrm{W} / \mathrm{m}^{2}\right)$ ) while subscript " $i$ " refers to either the cathode "+" or anode "-". Here, $\Delta V_{i}$ is the voltage difference measured in each heat flux sensor in thermal contact with electrode " $i$ ". The total instantaneous heat generation rate in the entire device was the sum of the heat generation rate measured at each electrode, i.e., $\dot{Q}_{T}(t)=\dot{Q}_{+}(t)+\dot{Q}_{-}(t)$.

\section{Results and discussion}

\subsection{Structural characterization}

Figure 2(a) shows a high resolution synchrotron X-ray diffraction (XRD) diagram of $\mathrm{TiNb}_{2} \mathrm{O}_{7}$ prepared using the previously described synthesis method. The XRD pattern was consistent with those prepared by conventional methods [23]. The pristine $\mathrm{TiNb}_{2} \mathrm{O}_{7}$ particles formed an electrically insulating white powder [42]. Figure 2(b) shows a SEM image of the synthesized $\mathrm{TiNb}_{2} \mathrm{O}_{7}$ particles typically less than $5 \mu \mathrm{m}$ and smaller than the average particle size of $20 \mu \mathrm{m}$ synthesized by solid state method [23]. Figure 2(c) illustrates the crystallographic structure of pure $\mathrm{TiNb}_{2} \mathrm{O}_{7}$ featuring a Wadsley-Roth crystallographic shear structure similar to those of $\mathrm{ReO}_{3}$ and $\mathrm{PNb}_{9} \mathrm{O}_{25}$ [42]. Overall, in stark contrast to the more conventional synthesis methods of transition metal oxide $\mathrm{TiNb}_{2} \mathrm{O}_{7}[21,23,24]$, the proposed method offers a much faster alternative. In fact, in less than 10 minutes in a standard microwave oven, the same compound was synthesized without necessitating any additional purification or annealing steps. An additional benefit of the present microwave preparation method was that the shorter heating time resulted in smaller $\mathrm{TiNb}_{2} \mathrm{O}_{7}$ particles. 


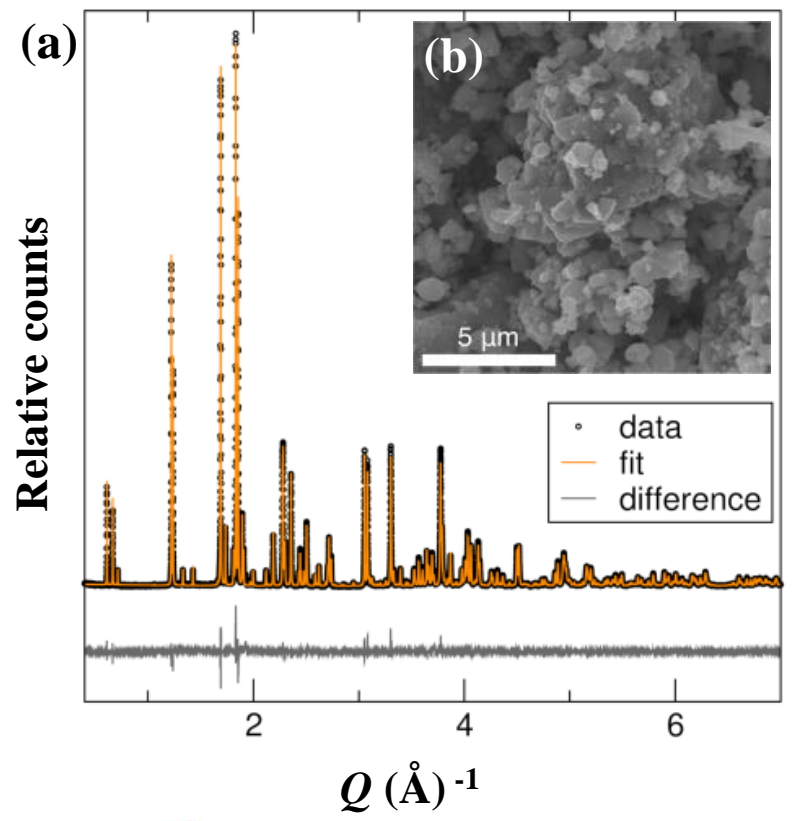

(c)

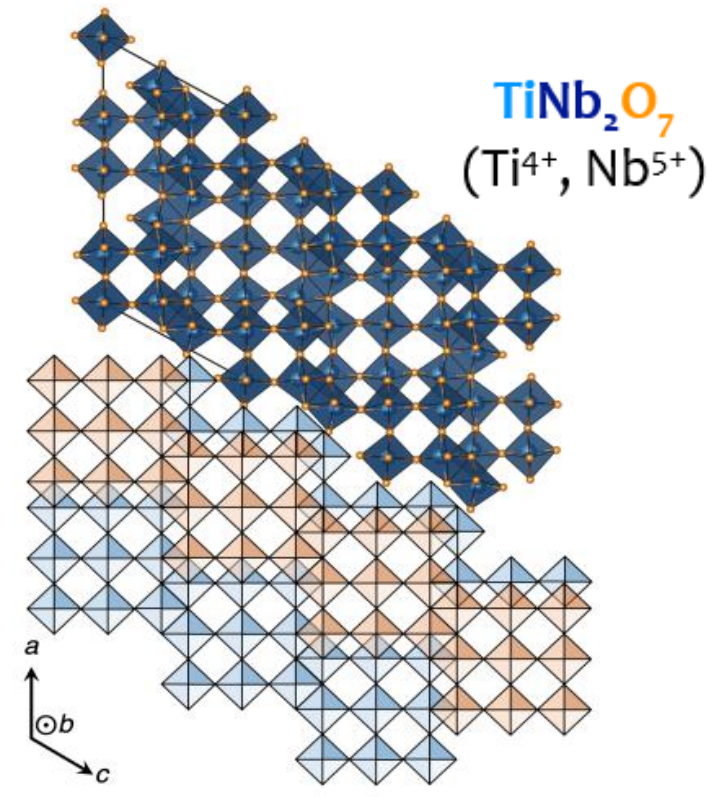

Figure 2: (a) Synchrotron X-ray diffraction pattern and (b) SEM image of the $\mathrm{TiNb}_{2} \mathrm{O}_{7}$ particles synthesized by the proposed microwave method, (c) crystallographic structure of pure $\mathrm{TiNb}_{2} \mathrm{O}_{7}$.

\subsection{Electrochemical properties}

Figure 3(a) shows the cyclic voltammogram of a $\mathrm{TiNb}_{2} \mathrm{O}_{7}$ based electrode at different scan rates between $1.0 \mathrm{~V}$ and $3.0 \mathrm{~V}$ (vs. $\mathrm{Li} / \mathrm{Li}^{+}$). A sharp cathodic peak at $1.58 \mathrm{~V}$ and an anodic 
peak at $1.7 \mathrm{~V}$ were observed at scan rate of $0.1 \mathrm{mV} / \mathrm{s}$. These two major peaks corresponded to the conversion of $\mathrm{Nb}^{5+} / \mathrm{Nb}^{4+}$ and were consistent with previous reports $[11,23,45,46]$. In
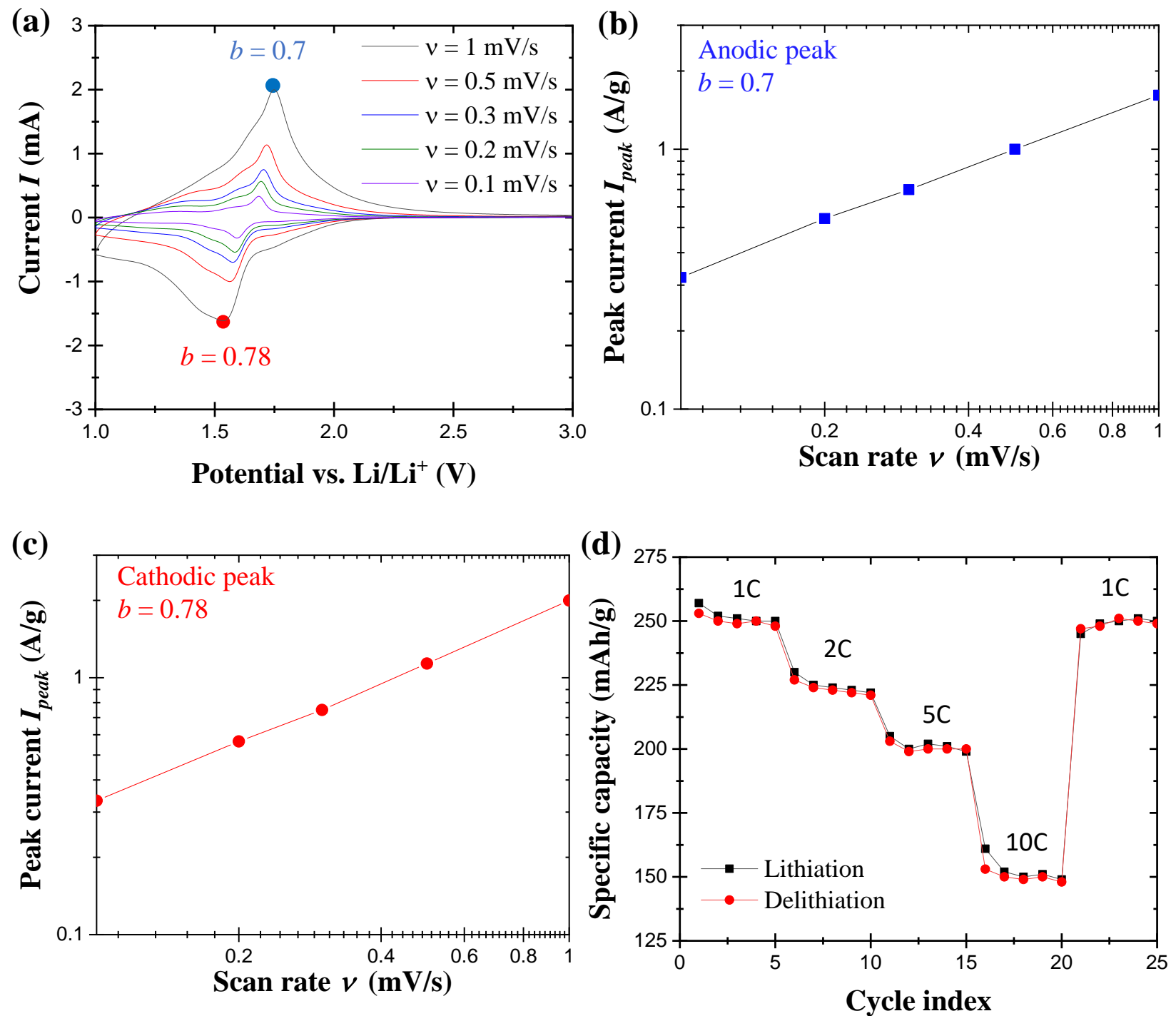

Figure 3: (a) cyclic voltammogram of $\mathrm{TiNb}_{2} \mathrm{O}_{7}$ half-cell cycled with a potential window ranging from 1.0 to $3.0 \mathrm{~V}$ vs. $\mathrm{Li} / \mathrm{Li}^{+}$at different scan rates $\nu$, (b) measured peak current $I_{\text {peak }}$ as a function of $\nu$ for anodic peak, and (c) for cathodic peak, (d) specific capacity retention of the $\mathrm{TiNb}_{2} \mathrm{O}_{7}$ at various C-rate in the voltage range of 1.0-3.0 V.

addition, one pair of shoulder peaks at $1.5 \mathrm{~V}$ for the cathodic sweep and at $1.62 \mathrm{~V}$ for the anodic sweep might be caused by different niobium states which are edge-shared octahedral and corner shared octahedral $[23,45,46]$. The pair of broad peaks in the potential range of 
1.0 to $1.4 \mathrm{~V}$ may be caused by the $\mathrm{Nb}^{4+} / \mathrm{Nb}^{3+}$ redox couple $[23,45,46]$. Another pair of a broad peak in the potential range of 1.75 to $2.0 \mathrm{~V}$ was associated with the conversion of $\mathrm{Ti}^{4+} / \mathrm{Ti}^{3+}[45,46]$. In addition, Figures $3(\mathrm{~b})$ and $3(\mathrm{c})$ show the peak current $I_{\text {peak }}$ values measured at differnt scan rates $\nu$ for the cathodic peak, and anodic peak respectively. The b-value of the cathodic and anodic peaks were obtained by calculating the index of the power law fit of the $I_{\text {peak }}$ versus scan rate $\nu$, i.e., $I_{\text {peak }}=a \nu^{b}$. The b-value of the cathodic peak was found to be 0.78 and that of the anodic peak was 0.7 . The b-values in the range of 0.7-0.8 suggests that the $\mathrm{TiNb}_{2} \mathrm{O}_{7}$ goes through a fast redox reaction with relatively low diffusion limitation.

Figure 3(d) shows the capacity retention of $\mathrm{TiNb}_{2} \mathrm{O}_{7}$ at various C-rates also for a potential window between $1.0 \mathrm{~V}$ and $3.0 \mathrm{~V}$ (vs. $\mathrm{Li} / \mathrm{Li}^{+}$). The theoretical capacity of $\mathrm{TiNb}_{2} \mathrm{O}_{7}$ is estimated to be $388 \mathrm{mAh} / \mathrm{g}$ upon 5 lithium ion insertion [21]. Here, the measured reversible capacity of the $\mathrm{TiNb}_{2} \mathrm{O}_{7}$ electrode was around $255 \mathrm{mAh} / \mathrm{g}$ at C-rate of $1 \mathrm{C}$. At C-rate of $2 \mathrm{C}$, the $\mathrm{TiNb}_{2} \mathrm{O}_{7}$ electrode provided up to $60 \%$ of its theoretical capacity while graphite anode can only provide $22 \%$ of its theoretical capacity for the same C-rate [47]. Furthermore, even at rate of $10 \mathrm{C}$, the $\mathrm{TiNb}_{2} \mathrm{O}_{7}$ electrode maintained $40 \%$ of its theoretical capacity and showed impressive reversibility over a number of cycles.

\subsection{Partial molar entropy of $\mathrm{TiNb}_{2} \mathrm{O}_{7}$}

Figure 4(a) plots the cell voltage $V(x, t)$ and open circuit voltage $U_{\text {ocv }}(x, T)$ as functions of $x$ composition in $\mathrm{Li}_{x} \mathrm{TiNb}_{2} \mathrm{O}_{7}$ measured by GITT at C-rate of $2 \mathrm{C}$ and temperature $T=20$ ${ }^{\circ} \mathrm{C}$. It features three distinct regions apparent in the slope of the open circuit voltage curve during the incorporation process of $\mathrm{Li}^{+}$in $\mathrm{Li}_{x} \mathrm{TiNb}_{2} \mathrm{O}_{7}$. The first sharp drop in $U_{\text {ocv }}(x, T)$ in the range $0.0 \leq x \leq 0.75$ was indicative of a homogeneous solid solution [11]. Then, the voltage plateau in the range $0.75 \leq x \leq 1.5$ corresponded to a two phase coexistence region, as discussed in the literature $[11,21]$. Finally, the shallow slope for $1.5 \leq x \leq 3.0$ corresponded to another homogeneous solid solution [11,21].

Figure 4(b) shows the measured partial molar entropy $\bar{s}(x, T)$ and open circuit voltage 

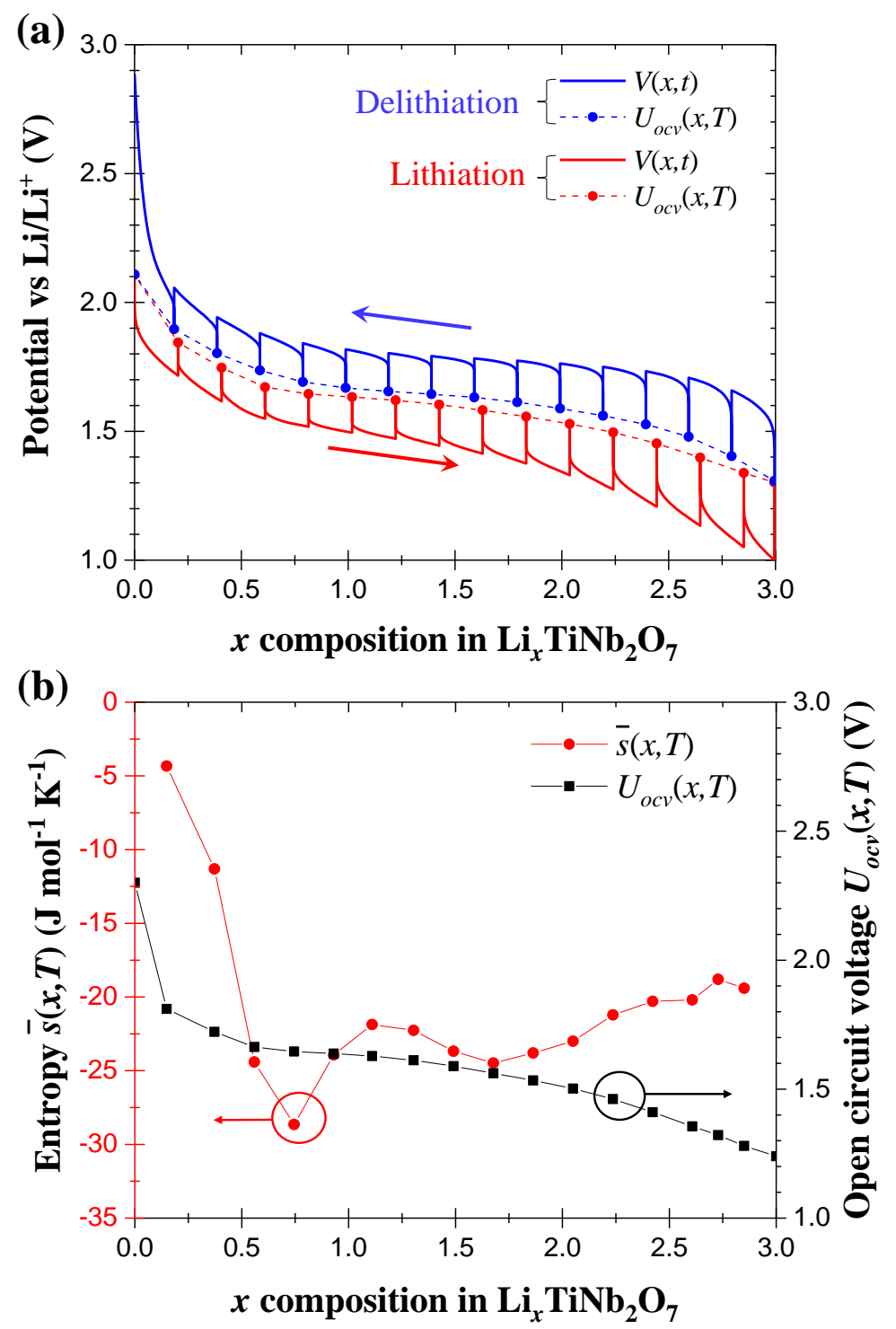

Figure 4: Galvanostatic intermittent titration technique (GITT) curve plotting (a) cell potential $V(x, t)$ and open circuit voltage $U_{o c v}(x, T)$ during delithiation and lithiation as functions of lithium composition $x$ in $\mathrm{Li}_{x} \mathrm{TiNb}_{2} \mathrm{O}_{7}$; (b) partial molar entropy $\bar{s}(x, T)$ and open circuit voltage $U_{\text {ocv }}(x, T)$ as functions of $x$ during lithiation. Both measurements were taken at C-rate of $2 \mathrm{C}$ and temperature $T=20{ }^{\circ} \mathrm{C}$.

$U_{\text {ocv }}(x, T)$ of the $\mathrm{TiNb}_{2} \mathrm{O}_{7}$ half-cell as functions of lithium composition $x$ in $\mathrm{Li}_{x} \mathrm{TiNb}_{2} \mathrm{O}_{7}$ during lithiation at $20{ }^{\circ} \mathrm{C}$. The measurements were found to be in a good agreement with 
previous studies [22]. Indeed, $\bar{s}(x, T)$ was negative throughout the entire lithium composition upon lithium insertion. Therefore, the reversible entropic heat generation was expected to be strictly exothermic $\left(\dot{Q}_{r e v} \geq 0\right)$ during lithiation and endothermic $\left(\dot{Q}_{r e v} \leq 0\right)$ during delithiation. For $x<0.75$, the entropy $\bar{s}(x, T)$ decreased rapidly upon insertion of lithium in the homogeneous solid solution forming a more ordered structure [22]. However, the entropy $\bar{s}(x, T)$ started to increase around $x=0.75$ due to the transition from a homogeneous solid solution to a two-phase coexistence region. The in situ XRD data reported in literature $[11,50]$ shows that all the $\operatorname{TiNb}_{2} \mathrm{O}_{7}$ reflections were maintained upon lithiation/delithiation for all values of $x$. Therefore, the structure of both homogeneous solid solution phases was in the monoclinic phase with the identical $\mathrm{C} / 2 \mathrm{~m}$ space group and $\mathrm{TiNb}_{2} \mathrm{O}_{7}$ did not experience crystallographic phase transition [50]. However, $\bar{s}(x, T)$ experienced fluctuation in the composition range $0.75 \leq x \leq 1.5$ corresponding to a two-phase coexistence region. Since a crystallographic phase change did not occur, the observed fluctuation in $\bar{s}(x, T)$ was influenced by the intralayer lithium ordering rather than by a first order phase transition. This type of tilde shape entropy change was first observed by Dahn and Haering [51] upon lithiation of $\mathrm{TiS}_{2}$. It occurs when it is energetically favorable for the inserted lithium ions in the lattice to arrange themselves in the vacancies in a more ordered fashion than being randomly inserted for further insertion of lithium ions [35]. This intralayer lithium reordering corresponds to rapid lithium mobility within the Wadsley-Roth block motifs down the tunnels along the b-axis and also between intrablock tunnels as reported in previous literature [42]. For $x>1.5, \bar{s}(x, T)$ was nearly constant within a range of -20 to $-25 \mathrm{~J} / \mathrm{mol} \cdot \mathrm{K}$ indicating the filling of leftover vacancy sites in the shear structure of the homogeneous solid solution [22].

\subsection{Heat generation of $\mathrm{TiNb}_{2} \mathrm{O}_{7}$}

Figure 5(a) plots the irreversible Joule heat generation rate $\dot{Q}_{J}(x, t)$ during lithiation, and delithiation calculated from Eq.(1) based on the imposed current $I$, the cell voltage $V(x, t)$ measured in the calorimeter under galvanostatic cycling at C-rate of $2 \mathrm{C}$, and the open circuit voltage $U_{\text {ocv }}(x, T)$ measured by GITT at $20{ }^{\circ} \mathrm{C}$. The change observed in $\dot{Q}_{J}(x, t)$ 
could be attributed to changes in the electrical resistivity of $\mathrm{TiNb}_{2} \mathrm{O}_{7}$ upon lithiation. Indeed, $\mathrm{TiNb}_{2} \mathrm{O}_{7}$ is an insulator in its unlithiated state, and exhibits very large electrical resistivity $10^{9} \Omega \mathrm{cm}[52]$. However, upon lithiation to $\mathrm{Li}_{0.25} \mathrm{TiNb}_{2} \mathrm{O}_{7}$, the electrical resistivity decreases by seven orders of magnitude to $\sim 50 \Omega \mathrm{cm}[52]$. This change in electrical resistivity was well captured by the sharp drop in $\dot{Q}_{J}(x, t)$ in the composition range $0 \leq x \leq 0.9$. Furthermore, the electrical resistivity slightly increased again upon further lithium ion insertion. In fact, the electrical resistivity was measured to be $\sim 700 \Omega \mathrm{cm}$ for $\mathrm{LiTiNb}_{2} \mathrm{O}_{7}$ and $\sim 2000 \Omega \mathrm{cm}$ for $\mathrm{Li}_{2.5} \mathrm{TiNb}_{2} \mathrm{O}_{7}$ [52]. This increase in the electrical resistivity of $\mathrm{Li}_{x} \mathrm{TiNb}_{2} \mathrm{O}_{7}$ was also captured by $\dot{Q}_{J}(x, t)$ for composition $x$ in the range $0.9 \leq x \leq 3$. However, $\dot{Q}_{J}(x, t)$ during delithiation differed from that during lithiation possibly due to the difference in mass transfer resistance associated with $\mathrm{Li}^{+}$diffusion in the electrode.
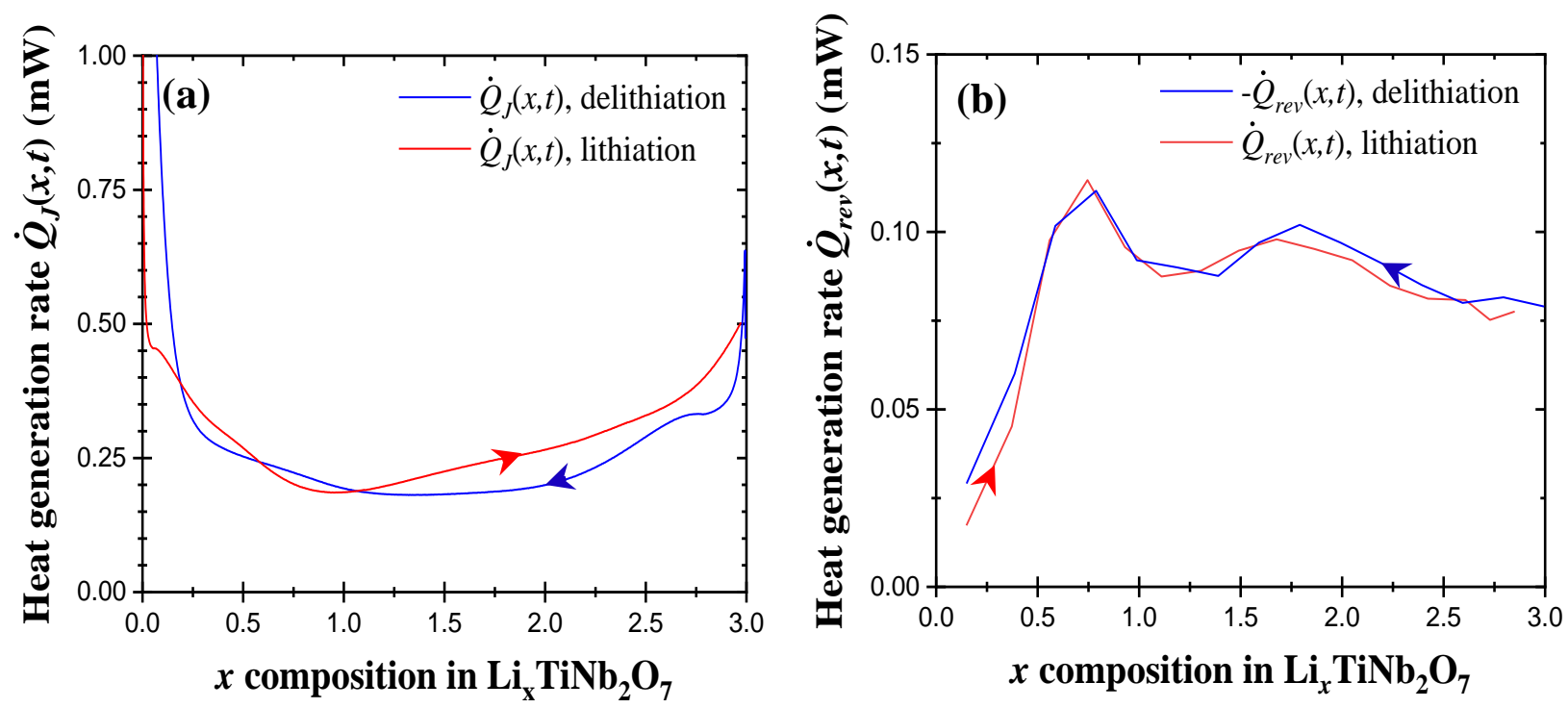

Figure 5: (a) Irreversible Joule heat generation rate $\dot{Q}_{J,}(x, t)$ during lithiation, and delithiation [Eqs.(1)], and (b) reversible heat generation rate $\dot{Q}_{r e v}(x, t)$ during lithiation and delithiation [Eqs.(2)] as functions of lithium composition $x$ in $\mathrm{Li}_{x} \mathrm{TiNb}_{2} \mathrm{O}_{7}$ at temperature $T=20$ ${ }^{\circ} \mathrm{C}$.

Moreover, Figure 5(b) shows the reversible heat generation rate $\dot{Q}_{r e v}(x, t)$ during lithi- 
ation, and delithiation estimated using Eq.(2) based on the measured entropic potential $\partial U_{\text {ocv }}(x, T) / \partial T$. Here, $\dot{Q}_{r e v}(x, t)$ was exothermic (i.e., positive) upon lithiation and endothermic (i.e., negative) upon delithiation. The effect of $\dot{Q}_{r e v}(x, t)$ became significant as $\mathrm{Li}_{x} \mathrm{TiNb}_{2} \mathrm{O}_{7}$ transitioned from a homogeneous solid solution to two coexisting solid phases around $x \simeq 0.75$. After the sharp change, $\dot{Q}_{r e v}(x, t)$ remained fairly constant for the rest of the lithiation process. Note also that integrating $\dot{Q}_{r e v}(x, t)$ over an entire cycle yielded nearly zero, confirming the reversible nature of this heat generation mechanism.

Figures $6(\mathrm{a})$ and $6(\mathrm{~b})$ plot the instantaneous heat generation rate $\dot{Q}_{T}(x, t)$ measured in the calorimeter cell at C-rate of $2 \mathrm{C}$ and $20{ }^{\circ} \mathrm{C}$ as a function of $x$ in $\mathrm{Li}_{x} \mathrm{TiNb}_{2} \mathrm{O}_{7}$. The sum of $\dot{Q}_{J}(x, t)+\dot{Q}_{r e v}(x, t)$ was in relatively good agreement with the measured total heat generation rate $\dot{Q}_{T}(x, t)$. Assuming that the effect of heat generation due to side reactions $\dot{Q}_{s r}(x, t)$ was negligible [25-27], the difference between $\dot{Q}_{T}(x, t)$, and the sum $\dot{Q}_{J}(x, t)+\dot{Q}_{\text {rev }}(x, t)$ corresponded to the enthalpy of mixing, i.e., $\dot{Q}_{m i x}(x, t)=\dot{Q}_{T}(x, t)-\dot{Q}_{J}(x, t)-\dot{Q}_{r e v}(x, t)$ [Eq.(4)]. The heat dissipated due to enthalpy of mixing upon relaxation of quasi-steady state concentration gradients formed upon cycling was reported to be inversely proportional to the square of the apparent diffusion coefficient [38]. In fact, the apparent diffusion coefficient of lithium into the electrode, $D_{L^{+}}(x)$ can be estimated by combining GITT and Fick's second law according to [48]

$$
D_{L i^{+}}(x, T)=\frac{4}{\pi \tau}\left(\frac{V}{A}\right)^{2}\left(\frac{\Delta U_{o c v}(x, T)}{\Delta V_{t}(x)}\right)^{2} .
$$

Here, $\tau$ is the duration of the GITT current pulse, $A$ and $V$ are the surface area and the volume of the electrode, $\Delta V_{t}(x)$ is the change in the cell potential as a result of the imposed current pulses excluding the IR drop at the beginning of the current pulse, and $\Delta U_{\text {ocv }}(x, T)$ is the change in the open circuit voltage between two consecutive current pulses. Figure 6(c) shows the apparent diffusion coefficient of $\mathrm{Li}^{+}$in the electrode $D_{\mathrm{Li}^{+}}(x)$ measured as a function of $x$ in $\mathrm{Li}_{x} \mathrm{TiNb}_{2} \mathrm{O}_{7}$ at $20^{\circ} \mathrm{C}$. It reached a minimum of $8 \times 10^{-12} \mathrm{~cm}^{2} / \mathrm{s}$ at $x_{\text {min }} \simeq$ 0.8 during lithiation and at $x_{\text {min }} \simeq 1.4$ during delithiation. Interestingly, these values of $x_{\text {min }}$ corresponded closely to the bounds of the voltage plateau (at $U_{\text {ocv }}=1.6 \mathrm{~V}$ ) observed in the GITT curve (Fig. 4). This indicates that the very sharp decrease in $D_{L^{+}}(x)$ was 
(a)

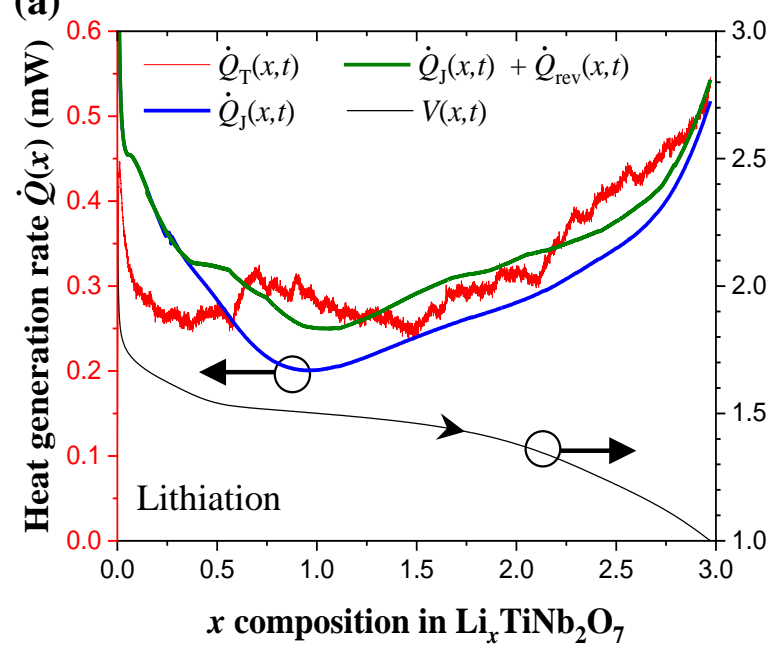

(c)



(b)

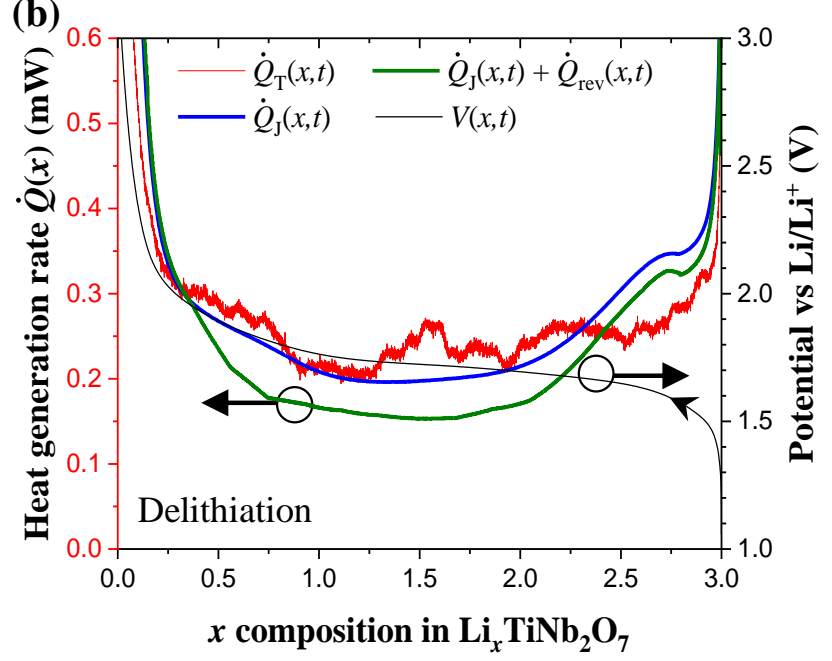

(d)

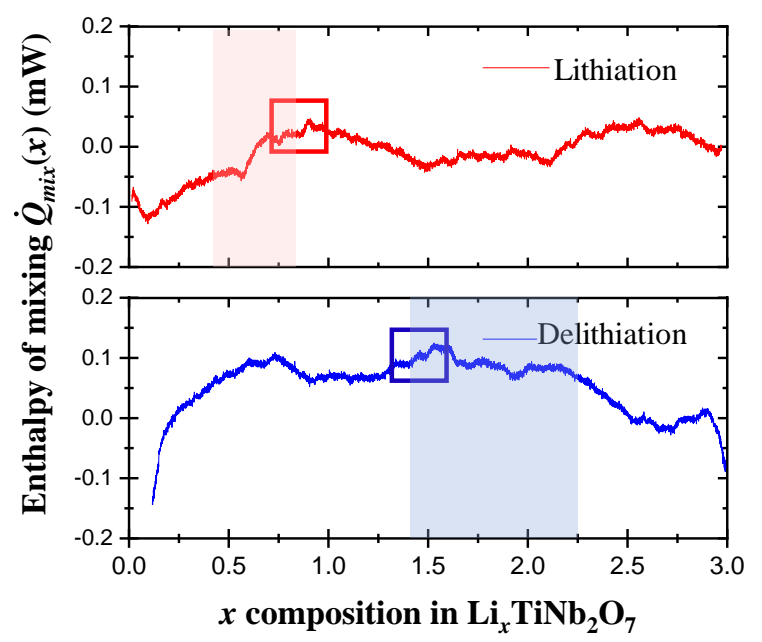

Figure 6: Heat generation rates $\dot{Q}_{T}(x, t), \dot{Q}_{J}(x, t), \dot{Q}_{J}(x, t)+\dot{Q}_{\text {rev }}(x, t)$ [Eqs.(1),(2),(5)] and cell voltage $V(x, t)$ measured upon (a) lithiation, (b) delithiation at C-rate of $2 \mathrm{C}$ at $20{ }^{\circ} \mathrm{C}$. (c) Apparent diffusion coefficient $D_{L i^{+}}$of lithium ion in $\mathrm{Li}_{x} \mathrm{TiNb}_{2} \mathrm{O}_{7}$ and (d) enthalpy of mixing $\dot{Q}_{m i x}(x, t)=\dot{Q}_{T}(x, t)-\left[\dot{Q}_{J}(x, t)+\dot{Q}_{r e v}(x, t)\right]$ as functions of lithium composition $x$ in $\mathrm{Li}_{x} \mathrm{TiNb}_{2} \mathrm{O}_{7}$ at temperature $T=20{ }^{\circ} \mathrm{C}$.

caused by the transition from a homogeneous solid solution phase reaction to a two-phase coexistence region [49]. In addition, this change in the apparent diffusion coefficient was also observed with the enthalpy of mixing $\dot{Q}_{m i x}$. During the lithiation process, a significant drop in $D_{L i^{+}}(x, T)$ was observed for $0.4 \leq x \leq 0.8$. This contributed to an increase in the 
enthalpy of mixing $\dot{Q}_{m i x}(x, t)$ and to its local maximum highlighted in Figure 6(d). Similarly, the sharp decrease in $D_{L i^{+}}(x, T)$ during delithiation between $2.25 \geq x \geq 1.4$ correlated with an increase in the enthalpy of mixing and the local maximum highlighted in Figure 6(d).



Figure 7: Net electrical energy losses $\Delta E_{e}$ and total thermal energy dissipated $Q_{T}$ for the first five charging-discharging cycles as well as that due to Joule heating $Q_{J}$ during lithiation and delithiation. The enthalpy of mixing corresponds to $Q_{m i x}=Q_{T}-Q_{J}=\Delta E_{e}-Q_{J}$.

A recent experimental study demonstrated that the net electrical energy losses due to the hysteretic voltage profile upon cycling were dissipated as Joule heating at low C-rate [26]. By operating at C-rate of $\mathrm{C} / 10$, the authors were able to neglect the effect of enthalpy of mixing [26]. However, the latter can be significant in fast charging batteries operating under high currents [38]. Here, the net electrical energy losses $\Delta E_{e}$ (in J) between the electrical energy provided during charging and that recovered during discharging was illustrated in the 
hysteric voltage $V(x, t)$ and expressed as [26]

$$
\Delta E_{e}=\oint_{c y c l e} V(x, t) d q
$$

where $q$ is the charge transferred upon electrochemical reaction. The total thermal energy dissipated $Q_{T}$ (in $\mathrm{J}$ ) as well as the heat dissipated in the form of Joule heating $Q_{J}$ and enthalpy of mixing $Q_{m i x}$ were calculated according to [26]

$$
Q_{i}=\oint_{\text {cycle }} \dot{Q}_{i}(x, t) d t \quad \text { with } i=T, J, \text { rev, or } m i x
$$

Figure 7 presents the electrical energy losses $\Delta E_{e}$ over the first five cycles and the total thermal energy dissipated $Q_{T}$ along with that due to Joule heating $Q_{J}$ during lithiation and delithiation. Figure 7 indicates that $\Delta E_{e}$ increased upon cycling possibly due to the associated increase in the internal resistance [31,32]. More importantly, $\Delta E_{e}$ fell within $2 \%$ of the measured total thermal energy $Q_{T}$ generated per cycle, i.e., the electrical energy losses were dissipated entirely in the form of heat, i.e., $\Delta E_{e}=Q_{T}$. In addition, the irreversible Joule heating during lithiation was larger than that during delithiation due to the slower kinetics of lithiation characterized by a smaller apparent diffusion coefficient compared to delithiation resulting in a larger overpotential [53]. Since $Q_{\text {rev }} \simeq 0$, the difference between $Q_{T}$ and $Q_{J}$ represented the heat dissipated as enthalpy of mixing $Q_{\text {mix }}$. Over the first five cycles, the irreversible Joule heating was responsible for $85 \%$ of the total energy dissipated while the enthalpy of mixing contributed only $15 \%$. By contrast, calculations based on isothermal calorimetry on $\mathrm{LiAl}_{0.2} \mathrm{Mn}_{1.8} \mathrm{O}_{4-\delta} \mathrm{F}_{0.2}$ showed that the energy dissipated in the form of enthalpy of mixing was $52 \%$ of total dissipated heat at the same rate with the same electrolyte and counter electrode [38]. The present results indicate that the heat dissipation due to the enthalpy of mixing remained small in the calorimeter cell even at a C-rate of $2 \mathrm{C}$ which is very promising for fast charging battery applications. 


\section{Conclusion}

This paper reports a fast, simple, and inexpensive synthesis method of small $\mathrm{TiNb}_{2} \mathrm{O}_{7}$ particles, requiring a mere 7 minutes in a microwave oven under an ambient atmosphere. This preparation method presents new opportunities for reducing the production costs and synthesis times of LIBs anode with excellent performance at high C-rates. The synthesized $\mathrm{TiNb}_{2} \mathrm{O}_{7}$ particles were smaller than those synthesized with conventional solid state methods. Entropy measurements combined with previous in situ XRD measurements [11,50] established the occurrence of intralayer lithium ordering enabling the fast charging of $\mathrm{TiNb}_{2} \mathrm{O}_{7}$. In addition, the heat generation rate due to Joule heating varied widely during lithiation and delithiation and dominated the energy losses during cycling at C-rate of 2C. Such calorimetric measurements can further provide insight into changes in the electrical conductivity of batteries for different SOC upon cycling. Furthermore, the enthalpy of mixing remained small even at high c-rates and correlated with changes in the measured apparent diffusion coefficient of $\mathrm{Li}^{+}$in the $\mathrm{Li}_{x} \mathrm{TiNb}_{2} \mathrm{O}_{7}$ electrode upon lithiation/delithiation. These results establish that $\mathrm{TiNb}_{2} \mathrm{O}_{7}$ constitutes an excellent anode material for fast charging battery applications.

\section{Acknowledgment}

This work was supported as part of the Center for Synthetic Control Across Length-scales for Advancing Rechargeables (SCALAR), an Energy Frontier Research Center funded by the U.S. Department of Energy, Office of Science, Basic Energy Sciences under Award \# DE-SC0019381.

\section{References}

[1] J. A. Rogers, "Electronics for the human body", Journal of the American Medical Association, vol. 313, no. 6, pp. 561-562, 2015. 
[2] H. Nishide and K. Oyaizu, "Toward flexible batteries", Science, vol. 319, no. 5864, pp. 737-738, 2008.

[3] H. Guo, M.-H. Yeh, Y. Zi, Z. Wen, J. Chen, G. Liu, C. Hu, and Z. L. Wang, "Ultralight cut-paper-based self-charging power unit for self-powered portable electronic and medical systems", ACS Nano, vol. 11, no. 5, pp. 4475-4482, 2017.

[4] A. Meintz, J. Zhang, R.Vijayagopal, C.Kreutzer, S.Ahmed, I. Bloom, A. Burnham, R.B. Carlson, F. Dias, E.-J. Dufek, J. Francfort, K. Hardy, A.-N. Jansen, M. Keyser, A. Markel, C. Michelbacher, M. Mohanpurkar, A. Pesaran, D. Scoffield, M. Shirk, T. Stephens, and T. Tanim, "Enabling fast charging - Vehicle considerations", Journal of Power Sources, vol. 367, no. 5, pp. 216-227, 2017.

[5] M. Walter, M.V. Kovalenko, and K.V. Kravchyk, "Challenges and benefits of postlithium-ion batteries", New Journal of Chemistry, vol. 44, no. 5, pp. 1677-1683, 2020.

[6] S. Flandrois, and B. Simon "Carbon materials for lithium-ion rechargeable batteries", Carbon, vol. 37, no. 2, pp. 165-180, 1999.

[7] E. Peled, C. Menachem, D. Bar-Tow, and A, Melman "Improved graphite anode for lithium-ion batteries chemically bonded solid electrolyte interface and nanochannel formation", Journal of The Electrochemical Society, vol. 143, no. 1, pp. L4-L7, 1996.

[8] J.B. Goodenough, and Y. Kim "Challenges for rechargeable Li batteries", Chemistry of materials, vol. 22, no. 3, pp. 587-603, 2010.

[9] D. Aurbach, B. Markovsky, I. Weissman, E. Levi, and Y. Ein-Eli "On the correlation between surface chemistry and performance of graphite negative electrodes for $\mathrm{Li}$ ion batteries", Electrochimica Acta, vol. 45, no. 1-2, pp. 57-86, 1999.

[10] K. Amine, I. Belharouak, Z. Chen, T. Tran, H. Yumoto, N. Ota, S.-T. Myung, and Y.-K. Sun "Nanostructured anode material for high-power battery system in electric vehicles", Advanced Materials, vol. 22, no. 28, pp. 3052-3057, 2010. 
[11] B. Guo, X. Yu, X.-G. Sun, M. Chi, Z.-A. Qiao, J. Liu, Y.-S. Hu, X.-Q. Yang, J.B. Goodenough, and S. Dai "A long-life lithium-ion battery with a highly porous $\mathrm{TiNb}_{2} \mathrm{O}_{7}$ anode for large-scale electrical energy storage", Energy \& Environmental Science, vol. 7, no. 7, pp. 2220-2226, 2014.

[12] H. Liu, W. Li, D. Shen, D. Zhao, and G. Wang "Graphitic carbon conformal coating of mesoporous $\mathrm{TiO}_{2}$ hollow spheres for high-performance lithium ion battery anodes", Journal of the American Chemical Society, vol. 137, no. 40, pp. 13161-13166, 2015.6.

[13] "Preparation and electrochemical properties of $\mathrm{Ag}$-modified $\mathrm{TiO}_{2}$ nanotube anode material for lithium-ion battery", Electrochemistry Communications, vol. 9, no. 3, pp. 425-430, 2007.

[14] J. Wang, Y. Zhou, Y. Hu, R. O'Hayre, and Z. Shao "Facile synthesis of nanocrystalline $\mathrm{TiO}_{2}$ mesoporous microspheres for lithium-ion batteries", The Journal of Physical Chemistry C, vol. 115, no. 5, pp. 2529-2536, 2011.

[15] V. Aravindan, W.Chuiling, and S. Madhavi "High power lithium-ion hybrid electrochemical capacitors using spinel $\mathrm{LiCrTiO}_{4}$ as insertion electrode", Journal of Materials Chemistry, vol. 22, no. 31, pp. 16026-16031, 2012.

[16] X. Feng, C. Shen, N. Ding, and C. Chen "Lithium chromium oxide modified spinel $\mathrm{LiCrTiO}_{4}$ with improved electrochemical properties", Journal of Materials Chemistry, vol. 22, no. 39, pp. 20861-20865, 2012.

[17] K.-S. Park, A. Benayad, D.-K. Kang, and S.-G. Doo "Nitridation-driven conductive $\mathrm{Li}_{4} \mathrm{Ti}_{5} \mathrm{O}_{12}$ for lithium ion batteries", Journal of the American Chemical Society, vol. 130, no. 45, pp. 14930-14931, 2008.

[18] L. Zhao, Y.-S. Hu, H. Li, Z. Wang, and L. Chen "Porous $\mathrm{Li}_{4} \mathrm{Ti}_{5} \mathrm{O}_{12}$ coated with N-doped carbon from ionic liquids for Li-ion batteries", Advanced Materials, vol. 23, no. 11, pp. 1385-1388, 2011. 
[19] J. Huang, and Z. Jiang "The preparation and characterization of $\mathrm{Li}_{4} \mathrm{Ti}_{5} \mathrm{O}_{12} /$ carbon nano-tubes for lithium ion battery", Electrochimica Acta, vol. 53, no. 26, pp. 7756$7759,2008$.

[20] B. Zhao, R. Ran, M. Liu, and Z. Shao "A comprehensive review of $\mathrm{Li}_{4} \mathrm{Ti}_{5} \mathrm{O}_{12}$-based electrodes for lithium-ion batteries: The latest advancements and future perspectives", Materials Science and Engineering: R: Reports, vol. 98, pp. 1-71, 2015.

[21] J.-T. Han, Y.-H. Huang, and J.B. Goodenough "New anode framework for rechargeable lithium batteries", Chemistry of Materials, vol. 23, no. 8, pp. 2027-2029, 2011.

[22] N. Takami, K. Ise, Y. Harada, T. Iwasaki, T. Kishi, and K. Hoshina "High-energy, fast-charging, long-life lithium-ion batteries using $\mathrm{TiNb}_{2} \mathrm{O}_{7}$ anodes for automotive applications", Journal of Power Sources, vol. 396, pp. 429-436, 2018.

[23] X. Lu, Z. Jian, Z. Fang, L. Gu, Y.-S. Hu, W. Chen, Z. Wang, and L. chen "Atomicscale investigation on lithium storage mechanism in $\mathrm{TiNb}_{2} \mathrm{O}_{7}$ ", Energy $\&$ Environmental Science, vol. 4, no. 8, pp. 2638-2644, 2011.

[24] K. Ise, S. Morimoto, Y. Harada, and N. Takami "Large lithium storage in highly crystalline $\mathrm{TiNb}_{2} \mathrm{O}_{7}$ nanoparticles synthesized by a hydrothermal method as anodes for lithium-ion batteries", Solid State Ionics, vol. 320, pp. 7-15, 2018.

[25] G. Liu, M. Ouyang, L. Lu, J. Li, and X. Han "Analysis of the heat generation of lithium-ion battery during charging and discharging considering different influencing factors", Journal of Thermal Analysis and Calorimetry, vol. 116, no. 2, pp. 1001-1010, 2014.

[26] G. Assat, S.L. Glazier, C. Delacourt, and J.-M. Tarascon "Probing the thermal effects of voltage hysteresis in anionic redox-based lithium-rich cathodes using isothermal calorimetry", Nature Energy, vol. 4, no. 8, pp. 647-656, 2019. 
[27] J. Newman, K.E. Thomas, H. Hafezi, and D.R. Wheeler "Modeling of lithium-ion batteries", Journal of Power Sources, vol. 119, pp. 838-843, 2003.

[28] D. Bernardi, E. Pawlikowski, and J. Newman "A general energy balance for battery systems", Journal of the Electrochemical Society, vol. 132, No. 1, pp. 5-12, 1985.

[29] V.V. Viswanathan, D. Choi, D. Wang, W. Xu, S. Towne, R.E. Williford, J.-G. Zhang, J. Liu, and Z. Yang "Effect of entropy change of lithium intercalation in cathodes and anodes on Li-ion battery thermal management", Journal of Power Sources, vol. 195, No. 11, pp. 3720-3729, 2010.

[30] X.-F. Zhang, Y. Zhao, Y. Patel, T. Zhang, W.-M. Liu, M. Chen, G.J Offer, and Y. Yan "Potentiometric measurement of entropy change for lithium batteries", Physical Chemistry Chemical Physics, vol. 19, No. 15, pp. 9833-9842, 2017.

[31] M. Ecker, J.B. Gerschler, J. Vogel, S. Käbitz, F. Hust, P.Dechent, and D.U. Sauer "Development of a lifetime prediction model for lithium-ion batteries based on extended accelerated aging test data", Journal of Power Sources, vol. 215, pp. 248-257, 2012.

[32] D. Andre, M. Meiler, K. Steiner, C. Wimmer, T. Soczka-Guth and D. Sauer "Characterization of high-power lithium-ion batteries by electrochemical impedance spectroscopy. I. Experimental investigation", Journal of Power Sources, vol. 196, No. 12, pp. 53345341, 2011.

[33] B. Yang, H. Zhang, L. Yu, W. Fan, and D. Huang "Lithium difluorophosphate as an additive to improve the low temperature performance of $\mathrm{LiNi}_{0.5} \mathrm{Co}_{0.2} \mathrm{Mn}_{0.3} \mathrm{O}_{2}$ /graphite cells", Electrochimica Acta, vol. 221, pp. 107-114, 2016.

[34] S. Ma, M. Jiang, P. Tao, C. Song, J. Wu, J. Wang, T. Deng, and W. Shang "Temperature effect and thermal impact in lithium-ion batteries: A review", Progress in Natural Science: Materials International, vol. 28, No. 6, pp. 653-666, 2018.. 
[35] N.S. Hudak, L.E. Davis, G. Nagasubramanian "Cycling-induced changes in the entropy profiles of lithium cobalt oxide electrodes", Journal of the Electrochemical Society, vol. 162, No. 3, pp. A315-A321, 2015.

[36] T. Tsujikawa, K. Yabuta, T. Matsushita, T. Matsushima, K. Hayashi, and M. Arakawa "Characteristics of lithium-ion battery with non-flammable electrolyte", Journal of Power Sources, vol. 189, No. 1, pp. 429-434, 2009.

[37] S. Zhao, F. Wu, L. Yang, L. Gao, and A.F.Burke "A measurement method for determination of dc internal resistance of batteries and supercapacitors", Electrochemistry Communications, vol. 12 , No. 2, pp. 242-245, 2010

[38] K.E. Thomas, and J. Newman "Thermal modeling of porous insertion electrodes", Journal of the Electrochemical Society, vol. 150, No. 2, pp. A176-A192, 2003.

[39] K.E. Thomas, and J. Newman "Heats of mixing and of entropy in porous insertion electrodes", Journal of Power Sources, vol. 119, pp. 844-849, 2003.

[40] A.A. Coelho "TOPAS and TOPAS-Academic: an optimization program integrating computer algebra and crystallographic objects written in $\mathrm{C}^{++}$, Journal of Applied Crystallography, vol. 51, No. 1 pp. 210-218, 2018.

[41] K. Momma, F. Izumi "VESTA 3 for three-dimensional visualization of crystal, volumetric and morphology data", Journal of applied crystallography, vol. 44, No. 6 pp. 1272-1276, 2011.

[42] K.J. Griffith, I.D. Seymour, M.A. Hope, M.M Butala, L.K. Lamontagne, M.B. Preefer, C.P. Kocer, G. Henkelman, A.J. Morris, and M.J. Cliffe "Ionic and electronic conduction in $\mathrm{TiNb}_{2} \mathrm{O}_{7}{ }^{\prime \prime}$, Journal of the American Ceramic Society, vol. 141, No. 42, pp. 16706$16725,2019$.

[43] S. Schlueter, R. Genieser, D. Richards, H.E. Hoster, and M.P. Mercer "Quantifying structure dependent responses in Li-ion cells with excess Li spinel cathodes: matching 
voltage and entropy profiles through mean field models", Physical Chemistry Chemical Physics, vol. 20, No. 33, pp. 21417-21429, 2018.

[44] O. Munteshari, J. Lau, A. Krishnan, B.S. Dunn, and L. Pilon, "Isothermal calorimeter for measurements of time-dependent heat generation rate in individual supercapacitor electrodes", Journal of Power Sources, vol. 374, pp. 257-268, 2018.

[45] H. Li, L. Shen, G. Pang, S. Fang, H. Luo, K. Yang, and X. Zhang " $\mathrm{TiNb}_{2} \mathrm{O}_{7}$ nanoparticles assembled into hierarchical microspheres as high-rate capability and long-cycle-life anode materials for lithium ion batteries", Nanoscale, vol. 7, No. 2, pp. 619-624, 2015.

[46] X. Wang, and G. Shen "Intercalation pseudo-capacitive $\mathrm{TiNb}_{2} \mathrm{O}_{7} @$ carbon electrode for high-performance lithium ion hybrid electrochemical supercapacitors with ultrahigh energy density", Nano Energy, vol. 15, pp. 104-115, 2015.

[47] H.-T. Kwon, J.-H. Kim, K.-J. Jeon, and C.-M. Park "Co ${ }_{x} \mathrm{P}$ compounds: electrochemical conversion/partial recombination reaction and partially disproportionated nanocomposite for Li-ion battery anodes", RSC Advances, vol. 4, No. 81, pp. 43227-43234, 2014.

[48] W. Weppner, and R.A. Huggins "Determination of the kinetic parameters of mixedconducting electrodes and application to the system $\mathrm{Li}_{3} \mathrm{Sb}^{\prime}$, Journal of The Electrochemical Society, vol. 124, No. 10, pp. 1569-1578, 1977.

[49] R. Inada, R. Kumasaka, S. Inabe, T. Tojo, and Y. Sakurai "Li+ insertion/extraction properties for $\mathrm{TiNb}_{2} \mathrm{O}_{7}$ single particle characterized by a particle-current collector integrated microelectrode", Journal of The Electrochemical Society, vol. 166, No. 3, pp. A5157-A5162, 2019.

[50] H. Yu, H. Lan, L. Yan, S. Qian, X. Cheng, H. Zhu, N. Long, M. Shui and J. Shu " $\mathrm{TiNb}_{2} \mathrm{O}_{7}$ hollow nanofiber anode with superior electrochemical performance in rechargeable lithium ion batteries", Nano Energy, vol. 38, pp. 109-117, 2017. 
[51] J. Dahn, and R.R. Haering "Lithium intercalation in $\mathrm{TiS}_{2}$ ", Materials Research Bulletin, vol. 14, No. 10, pp. 1259-1262, 1979.

[52] W. Xing, L.-E. Kalland, Z. Li, and R. Haugsrud "Defects and transport properties in $\mathrm{TiNb}_{2} \mathrm{O}_{7}$ ", Journal of the American Ceramic Society, vol. 96, No. 12, pp. 3775-3781, 2013.

[53] B. Babu, and M.M. Shaijumon "Studies on kinetics and diffusion characteristics of lithium ions in $\mathrm{TiNb}_{2} \mathrm{O}_{7}$ ", Electrochimica Acta, vol. 345, No. 10, pp. 136208, 2020. 